\title{
Mapeamento das Áreas de Preservação Permanente (APP) do município de Santo Antônio do Pinhal, SP: um subsídio à preservação ambiental
}

(doi:10.4136/ambi-agua.18)

\author{
Celso de Souza Catelani' ${ }^{1}$; Getulio Teixeira Batista ${ }^{2}$ \\ ${ }^{1}$ Geógrafo visitante do Laboratório de Geoprocessamento, Sensoriamento Remoto e Informática Rural da \\ Universidade de Taubaté (LAGEO) \\ E-mail: celso@agro.unitau.br \\ ${ }^{2}$ Professor do Programa de Pós-Graduação em Ciências Ambientais da Universidade de Taubaté (UNITAU) \\ E-mail: getulio@agro.unitau.br
}

\section{RESUMO}

O mapeamento das Áreas de Preservação Permanente (APPs) do município de Santo Antônio do Pinhal, SP, situado em uma área de grande interesse imobiliário na região serrana da Mantiqueira Paulista, especialmente pela proximidade do município turístico de Campos do Jordão, SP, deu-se, inicialmente, com o intuito de se produzir documentos cartográficos voltados a subsidiar as ações das autoridades ambientais responsáveis pela preservação destas áreas de APPs, já previstas na Lei 4.771/65 e, regulamentadas pelas Resoluções CONAMA 302 e 303/2002. Nesse contexto, este trabalho teve como objetivo a delimitação de APPs, na escala de 1:50.000, apoiado na utilização de técnicas no estado da arte das ferramentas computacionais de geoprocessamento e no tratamento de informações espaciais contidas em documento cartográfico oficial da Federação (Cartas Topográficas do IBGE na Escala de 1:50.000). Os resultados da análise e o mapeamento das áreas de preservação permanente do município de Santo Antônio do Pinhal demonstraram, em especial, duas situações de maior atenção: em primeiro lugar, destaca-se que as APPs abrangem uma área de 7.218 ha, equivalentes a 52,2\% da área total do município, um aspecto muito positivo do ponto de vista ambiental, porém extremamente restritivo em relação ao uso do solo. Em segundo, a ocorrência de APPs de Topo de Morro em uma área de 4.227 ha, correspondentes a 30,7\% da área total do município, o que demonstra o caráter restritivo ao uso da terra imposto por essa classe de APPs, especialmente em regiões com relevo ondulado como no domínio dos Mares de Morros em que se insere a área estudada.

Palavras-chave: áreas de preservação permanente; APP; legislação ambiental; geoprocessamento; SIG; SPRING.

\section{Mapping of Permanent Preservation Areas (PPA) of the municipal district of Santo Antônio do Pinhal, SP: base for environmental preservation}

\section{ABSTRACT}

The mapping of the Permanent Preservation Areas (PPAs) of the municipal district of Santo Antônio do Pinhal, SP, located in an area of great real estate interest in the Mantiqueira Moutains of São Paulo, neighbor of the touristic municipal district of Campos de Jordão, SP, became necessary. The need for producing cartographic documents is to support environmental authorities to establish plans for the preservation of these areas, especially the Permanent Preservation Areas (PPA) established by the Law 4,771/65 and regulated by the 
Resolutions CONAMA 302 and 303/2002. In that context, this work had as objective, the delimitation of Permanent Preservation Areas (PPA) at the 1:50,000 scale. The analysis and results of the mapping of the permanent preservation areas of the municipal district of Santo Antônio do Pinhal revealed two situations that deserve attention: first, the total area of PPAs corresponds to an area of 7,218ha which is equivalent to $52.2 \%$ of the total area of the municipal district. This is very positive for the environmental point of view, however, extremely restrictive for land use. The occurrence of PPAs in the class of "Top of Hills" reaches 4,227 ha which correspond to $30.7 \%$ of the total area of the municipal district. This demonstrates the restrictive character of land use of that PPA class, especially in areas with undulated relief as it is the case of the geomorphological domain known as "Mar de Morros" where the study area is located.

Keywords: permanent preservation areas; environmental legislation; geoprocessing; GIS; SPRING.

\section{INTRODUÇÃO}

O Vale do Paraíba sofreu ao longo do último século grande degradação ambiental por estar inserido entre os dois maiores pólos urbanos do país: São Paulo e Rio de Janeiro. Uma série de ciclos de exploração agrícola, como o da cana de açúcar e do café, substituídos pela agropecuária após a degradação dos solos devido à erosão, fez com que a derrubada da floresta primitiva se processasse de forma drástica. Há cem anos, apenas as formações florestais cobriam mais de 70\% do território paulista (Victor, 1979); hoje a cobertura vegetal nativa do Estado de São Paulo está estabilizada ao redor de 13,5\% da sua extensão territorial (Kronka et al., 2005). O Vale do Paraíba seguiu essa tendência de diminuição da cobertura vegetal nativa (Saito, 1995).

Por outro lado, o Código Florestal Brasileiro instituído em 1965 (Brasil, 1965), seguido por vários outros documentos legais, impõe restrições sobre o uso de áreas denominadas “Áreas de Preservação Permanente” (APPs). Nessas áreas não se pode fazer a retirada da cobertura vegetal original, para permitir, assim, o exercício pleno de suas funções ambientais (Ribeiro et al., 2005). No entanto, devido à tradição de uso intensivo do solo no passado e à dificuldade de imposição desse código, pouco se tem feito para verificar o uso atual dessas áreas.

Entretanto, existe hoje uma conscientização maior por parte da comunidade da necessidade de preservação dos recursos naturais, especialmente a partir da reunião de cúpula no Rio de Janeiro em 1992, onde foi assinada a Convenção sobre Mudanças Climáticas (MCT, 2002), seguida da instituição do Protocolo de Quioto (Miguez, 2002) sobre a redução da emissão de gases de efeito estufa, bem como o crescimento da atuação das ONGs ambientalistas. Seguindo essa preocupação, o Ministério Público no Estado de São Paulo tem atuado no sentido de fazer valer a legislação ambiental vigente. Há que se ressaltar a importância da preservação da vegetação de floresta para a melhoria da qualidade e quantidade de água, hoje, já em crise para o abastecimento da região (Rebouças et al., 1999), assim como, para a conservação da diversidade (Pincinato, 2005).

As técnicas de Geoprocessamento e Sensoriamento Remoto constituem, hoje, um importante conjunto de ferramentas aplicáveis ao planejamento geográfico para a obtenção de dados a serem utilizados no planejamento e zoneamento, tanto em níveis regionais quanto municipais. De fato, tem havido um desenvolvimento marcante das geotecnologias (Sensoriamento Remoto e Geoprocessamento) que disponibilizam uma série de ferramentas 
que auxiliam sobremaneira a investigação da adequação do uso do solo em áreas de preservação permanente (Aulicino et al., 2000; Costa et al., 1996). Entretanto, poucos trabalhos têm sido feitos para investigar e demonstrar a eficácia da tecnologia, especialmente na delimitação das áreas de usos restringidos pelo Código Florestal.

O município de Santo Antônio do Pinhal, situado na região da Serra da Mantiqueira, tem grande potencial turístico, especialmente na área rural, pelo seu clima de montanha, belezas naturais e sua localização ao lado do município de Campos do Jordão que é um dos maiores pólos turísticos do Estado. Além da importância socioeconômica, esse município foi escolhido para a validação da metodologia proposta pelas suas características geomorfológicas de região montanhosa que induzem um desafio maior na avaliação da tecnologia para a delimitação de APPs, especialmente de topo de morro.

Dessa forma, este trabalho teve como objetivo gerar um mapa contendo a delimitação das “Áreas de Preservação Permanente” previstas na legislação ambiental brasileira, de ocorrência no município (nascentes, margens de rios, declividade acima de $45^{\circ}$, altitude acima de $1.800 \mathrm{~m}$ e topo de morros, serras e montanhas) com base em mapas topográficos na escala 1:50.000 (IBGE, 1974), Código Florestal e posteriores documentos legais (Brasil, 1965; CONAMA, 1985 e 2002), por meio da geração de um modelo numérico do terreno utilizando funções no estado da arte de sistemas de informações geográficas disponibilizadas na versão do SPRING, v. 4.2 (Câmara et al., 1996), e, assim, gerar um produto que contém a representação cartográfica das áreas de preservação permanente (APPs) do município de Santo Antônio do Pinhal e apresentar uma abordagem metodológica do uso de geotecnologias na geração de um mapeamento da legislação ambiental sobre APPs.

\section{1. Áreas de Preservação Permanente}

As Áreas de Preservação Permanente (APPs) foram criadas para proteger o ambiente natural, o que significa que não são áreas apropriadas para alteração de uso da terra, Assim, essas áreas devem estar cobertas com a vegetação original. A cobertura vegetal nessas áreas irá atenuar os efeitos erosivos e a lixiviação dos solos, contribuindo também para regularização do fluxo hídrico, redução do assoreamento dos cursos d’água e reservatórios, e trazer também benefícios para a fauna (Costa et al., 1996). O Código Florestal Brasileiro define "As florestas existentes no território nacional e as demais formas de vegetação, reconhecidas de utilidade às terras que revestem, são bens de interesse comum a todos os habitantes do País, exercendo-se os direitos de propriedade, com as limitações que a legislação em geral e especialmente esta Lei estabelecem” (Art. $1^{\circ}$ Lei 4771/1965), conforme regulamentação no art. $2^{\circ}$ desta Lei ${ }^{\circ}$ 4.771, de 15 de setembro de 1965, (D.O.U. de 16/09/1965), no que concerne às Áreas de Preservação Permanente, as Resoluções CONAMA 302 e 303 de março de 2002 adotam novas definições com alterações significativas, principalmente, em relação às distâncias de fixação do limite de APPs, associadas à respectiva largura dos cursos d’água.

\section{MATERIAIS E MÉTODO}

\section{1. Área de Estudo}

Pela sua topografia e beleza natural, Santo Antônio do Pinhal é uma estância pioneira no turismo rural, muito visitada para a realização de esportes de montanha. Historicamente, a região foi desbravada por volta de 1720, pelos Bandeirantes. Em 1860, foi fundado oficialmente o povoado, dando-se a ele o nome de Santo Antônio do Pinhal em razão dos muitos pinheiros (Araucária angustifólia) existentes no local. 
Os solos do município, em quase sua totalidade, correspondem à classe Latossolo Vermelho Escuro com intrusões de Cambissolo Háplico (Kurkdijan et al., 1992). A área agricultável representa cerca de 690 ha em que aproximadamente 140 ha são culturas perenes, 110 ha semiperene e 450 ha de culturas anuais (LUPA, 1996). Segundo essa mesma fonte, o município apresenta: 5.610 ha em pastagens, 380 ha em reflorestamento e 2.160 ha de vegetação natural. Predominam no município as pequenas propriedades: 333 entre 0-50 ha, 49 entre 50-500 ha e nenhuma acima de 500 ha (LUPA, 1996). Segundo o IBGE (2000), a população rural em 2000 era de 3.297 indivíduos, enquanto a urbana era apenas de 3.031, o município situa-se na porção norte do cone leste paulista, próximo a Campos do Jordão e nas divisas com o Estado de Minas Gerais (Figura 1).

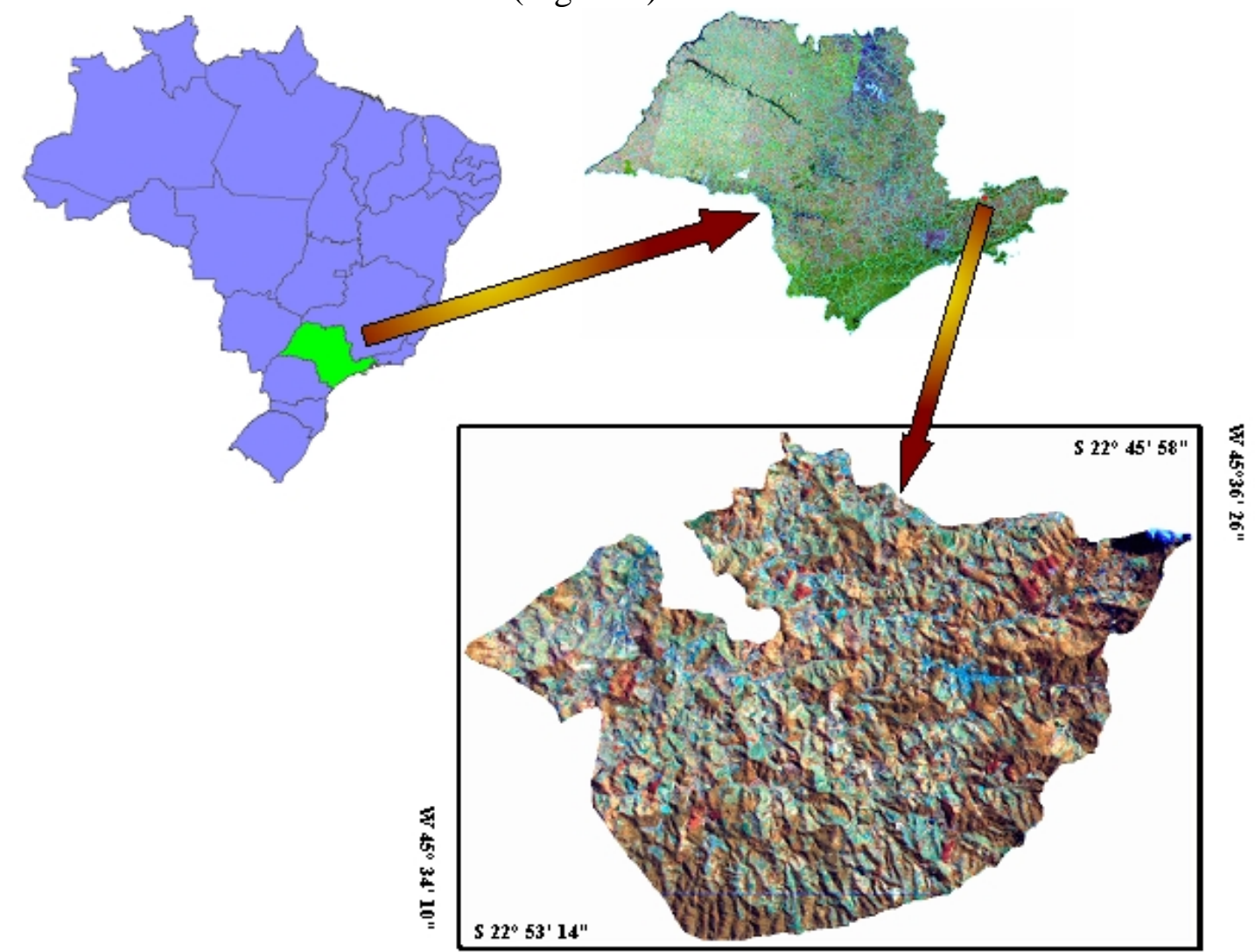

Figura 1. Localização da área de estudo correspondente aos limites do município de Santo Antônio do Pinhal em relação ao Brasil e Estado de São Paulo.

\subsection{Geração do Mapa de Áreas de Preservação Permanente}

\subsubsection{Fundamentação Legal}

A metodologia utilizada para execução do Mapeamento de Áreas Protegidas, em especial as Áreas de Preservação Permanente (APPs), foi baseada na Lei Federal Nº 4.771, de 1965 que instituiu o Código Florestal Brasileiro e nas Resoluções CONAMA No 04/1985 e N ${ }^{\text {os }} 302$ e 303/2002. De acordo com os critérios estabelecidos na legislação, as áreas protegidas foram mapeadas seguindo metodologia específica para cada uma das classes descritas na Resolução CONAMA 303/2002, transcrita a seguir e conforme Oliveira et al. (2006):

Art. $3^{\circ}$ Constitui Área de Preservação Permanente a área situada:

I - em faixa marginal, medida a partir do nível mais alto, em projeção horizontal, com largura mínima, de:

a) trinta metros, para o curso d água com menos de dez metros de largura; 
b) cinqüenta metros, para o curso d’água com dez a cinqüenta metros de largura;

c) cem metros, para o curso d’água com cinqüenta a duzentos metros de largura;

d) duzentos metros, para o curso d’água com duzentos a seiscentos metros de largura;

e) quinhentos metros, para o curso d’água com mais de seiscentos metros de largura;

II - ao redor de nascente ou olho d’água, ainda que intermitente, com raio mínimo de cinqüenta metros de tal forma que proteja, em cada caso, a bacia hidrográfica contribuinte;

III - ao redor de lagos e lagoas naturais, em faixa com metragem mínima de:

a) trinta metros, para as que estejam situados em áreas urbanas consolidadas;

b) cem metros, para as que estejam em áreas rurais, exceto os corpos d água com até vinte hectares de superfície, cuja faixa marginal será de cinqüenta metros;

IV - em vereda e em faixa marginal, em projeção horizontal, com largura mínima de cinqüenta metros, a partir do limite do espaço brejoso e encharcado;

V - no topo de morros e montanhas, em áreas delimitadas a partir da curva de nível correspondente a dois terços da altura mínima da elevação em relação à base;

VI - nas linhas de cumeada, em área delimitada a partir da curva de nível correspondente a dois terços da altura, em relação à base, do pico mais baixo da cumeada, fixando-se a curva de nível para cada segmento da linha de cumeada equivalente a mil metros;

VII - em encosta ou parte desta, com declividade superior a cem por cento ou quarenta e cinco graus na linha de maior declive;

VIII - nas escarpas e nas bordas dos tabuleiros e chapadas, a partir da linha de ruptura em faixa nunca inferior a cem metros em projeção horizontal no sentido do reverso da escarpa;

IX - nas restingas:

a) em faixa mínima de trezentos metros, medidos a partir da linha de preamar máxima;

b) em qualquer localização ou extensão, quando recoberta por vegetação com função fixadora de dunas ou estabilizadora de mangues;

$\mathrm{X}$ - em manguezal, em toda a sua extensão;

XI - em duna;

XII - em altitude superior a mil e oitocentos metros, ou, em estados que não tenham tais elevações, a critério do órgão ambiental competente;

XIII - nos locais de refúgio ou reprodução de aves migratórias;

XIV - nos locais de refúgio ou reprodução de exemplares da fauna ameaçadas de extinção que constem de lista elaborada pelo Poder Público Federal, Estadual ou Municipal;

XV - nas praias, em locais de nidificação e reprodução da fauna silvestre.

Parágrafo único. Na ocorrência de dois ou mais morros ou montanhas cujos cumes estejam separados entre si por distâncias inferiores a quinhentos metros, a Área de Preservação Permanente abrangerá o conjunto de morros ou montanhas, delimitada a partir da curva de nível correspondente a dois terços da altura em relação à base do morro ou montanha de menor altura do conjunto, aplicando- se o que segue:

I - agrupam-se os morros ou montanhas cuja proximidade seja de até quinhentos metros entre seus topos. 


\subsubsection{Tratamento Prévio dos Dados de Base}

A utilização de um SIG (Sistema de Informações Geográficas) para efetuar o mapeamento de áreas protegidas requer o tratamento prévio de camadas de informações geográficas, contendo os dados topográficos de planimetria, altimetria, declividade, rede de drenagem, corpos d’água e divisores topográficos de bacias (linhas de cumeada). Essas informações foram inseridas no banco de dados por meio da vetorização de cartas topográficas na escala de 1:50.000, contendo as curvas de nível com eqüidistância vertical de $20 \mathrm{~m}$ e a rede de drenagem. Esses dados foram processados, para se gerar uma grade triangular TIN (Triangular Irregular Network), utilizando-se a rede de drenagem correspondente como linhas de quebra. A partir da grade triangular resultante, foi gerada uma grade regular com resolução espacial de $20 \mathrm{~m}$, que assegura uma coordenada $3 \mathrm{D}$ a cada célula de $400 \mathrm{~m}^{2}$, caracterizando assim o MDT (Modelo Digital do Terreno) de todo o município. A partir da rede de drenagem foram gerados mapas de distância em metros, com valor 0 (zero), partindo da linha vetorial correspondente à rede de drenagem e dos pontos correspondentes às nascentes, esses inseridos no ponto inicial à montante de cada linha de drenagem. As linhas de cumeada foram geradas por meio da interpretação dos divisores topográficos pelo delineamento das curvas de nível, e traçadas em camada vetorial específica no banco de dados. Com a utilização da grade MDT gerada com base nos dados altimétricos, foram geradas grades de declividade da qual foram extraídos uma classe de APP (declividade $>45^{\circ}$ ) e um dado de apoio à delimitação de Topo de Morro, (Declividade > ou = a 30\%). A partir desse tratamento prévio dos dados, torna-se possível o Mapeamento das Áreas Protegidas, utilizando-se metodologia específica para cada uma das classes de APPs. (Aulicino et al., 2000).

A alternativa do uso de dados do Shuttle Radar Topography Mission (SRTM), no lugar das cartas topográficas 1:50.000, embora com vantagens operacionais, não seria viável para a escala de trabalho (nível municipal) devido à restrição da resolução espacial dos dados hoje disponíveis (Hott et al., 2005).

\subsection{Mapeamento de Áreas de Preservação Permanente (APP)}

\subsubsection{Mapeamento de APPs de Margens de Rios}

O mapeamento das APPs de margens de rios foi obtido por meio do mapa de distâncias da rede de drenagem, gerado com faixas de distância de 1,0m, que foi, posteriormente, fatiado com a distância de 30m (Buffer) em ambos os lados da drenagem, quando essa apresenta largura igual ou inferior a 10m, e 50m quando apresenta largura entre 10 e 50m.

\subsubsection{Mapeamento de APPs de Nascentes}

O mapeamento das APPs de entorno de nascentes foi obtido de forma semelhante ao mapeamento das APPs de Margens de Rios, porém utilizando-se como dado de entrada para a geração do mapa de distância, em metros, um plano de informação contendo somente os pontos correspondentes às nascentes. Desse plano de informações, foi gerado de forma análoga ao das margens, um mapa de distância com faixas de $1 \mathrm{~m}$ a partir de cada ponto correspondente às nascentes, esse mapa foi fatiado com valor correspondente a 50m de raio a partir do ponto central, para produzir o mapeamento da classe de APP de Nascentes.

\subsubsection{Mapeamento de APPs de Declividade Superior a $45^{\circ}$ ou $100 \%$}

A partir da grade do Modelo Digital do Terreno, previamente trabalhada como dado de base, foi gerada uma grade de declividade em graus, que foi, posteriormente, fatiada, gerando 
um mapa temático em que as áreas cuja declividade apresentou valores iguais ou superiores a $45^{\circ}$ ou $100 \%$ foram atribuídas à classe APPs de inclinação superior a 45 graus.

\subsubsection{Mapeamento de APPs de Topo de Morro e linha de cumeada}

O mapeamento de APPs de topo de morro (montes, serras e montanhas) e linha de cumeada depende de um aparato de apoio para a caracterização do relevo e a tomada dos pontos de cume e base de morro necessários ao cálculo do terço superior, que corresponde à área de preservação propriamente dita. Nesse contexto, foi necessária a criação de planos de informação, contendo em separado, Linhas de Cumeada, Grade Regular de Altimetria, Declividade igual ou superior a 30\%, Rede de Drenagem, Curvas de Nível e ainda um plano de informação vetorial criado especialmente para receber os polígonos correspondentes à classe Topo de Morro e linha de cumeada. Essa metodologia está de acordo com procedimentos da Secretaria do Meio Ambiente, Coordenadoria de Licenciamento Ambiental e Proteção de Recursos Naturais, Departamento Estadual de Proteção de Recursos Naturais (Oliveira et al., 2006).

Considerando-se os itens que devem ser obrigatoriamente observados para a delimitação dos topos de morro, foram então traçadas as curvas de nível que correspondem à delimitação do terço superior, delimitando-se assim a Área de Preservação Permanente de Topo de Morro e Linha de Cumeada. A interpretação dos morros, agrupamentos de morros ou ainda cadeia de morros e montanhas, levou em consideração a Resolução CONAMA n 303/2002, especificamente para esta classe de APP, como segue:

$\mathrm{V}$ - no topo de morros e montanhas, em áreas delimitadas a partir da curva de nível correspondente a dois terços da altura mínima da elevação em relação à base;

VI - nas linhas de cumeada, em área delimitada a partir da curva de nível correspondente a dois terços da altura, em relação à base, do pico mais baixo da cumeada, fixando-se a curva de nível para cada segmento da linha de cumeada equivalente a mil metros;

A mesma resolução estabelece ainda critérios para a caracterização do relevo para a delimitação dessa classe de APPs como segue:

IV - morro: elevação do terreno com cota do topo em relação à base entre cinqüenta e trezentos metros e encostas com declividade superior a trinta por cento (aproximadamente dezessete graus) na linha de maior declividade;

V - montanha: elevação do terreno com cota em relação à base superior a trezentos metros;

VI - base de morro ou montanha: plano horizontal definido por planície ou superfície de lençol d’água adjacente ou, nos relevos ondulados, pela cota da depressão mais baixa ao seu redor;

VII - linha de cumeada: linha que une os pontos mais altos de uma seqüência de morros ou de montanhas, constituindo-se no divisor de águas.

\subsection{Mapa de Áreas de Preservação Permanente}

Os dados obtidos individualmente no mapeamento de cada classe de APP foram, posteriormente, agrupados em um único plano de informação, obedecendo a uma ordem de prioridade arbitrária, convencionada pelos autores como ordem de importância decrescente, com a seguinte disposição das classes, $1^{\circ}$ Nascentes, $2^{\circ}$ Margens de Rios e Corpos D'Água, $3^{\circ}$ Declividade Superior a 45 graus ou $100 \%$, $4^{\circ}$ Altitude Superior a $1800 \mathrm{~m}$ e $5^{\circ}$ Topos de Morro e Linhas de Cumeada. Do agrupamento dessas classes num único plano de informações, obtém-se um Mapa de Áreas de Preservação Permanente sem que exista uma sobreposição de áreas, dando origem ao mapa final de Áreas de Preservação Permanente. 


\section{RESULTADOS E DISCUSSÃO}

Com base na metodologia descrita, as Figuras 2 e 3 exemplificam o mapeamento das APPs de margens de rio.

De forma similar, as Figuras 4 e 5 exemplificam o resultado do mapeamento de APPs de nascentes.

A Figura 6 mostra a grade regular das cotas altimétricas correspondentes ao Modelo Digital do Terreno, gerada no software SPRING e a Figura 7 exemplifica o resultado do mapeamento da APP de declividade.

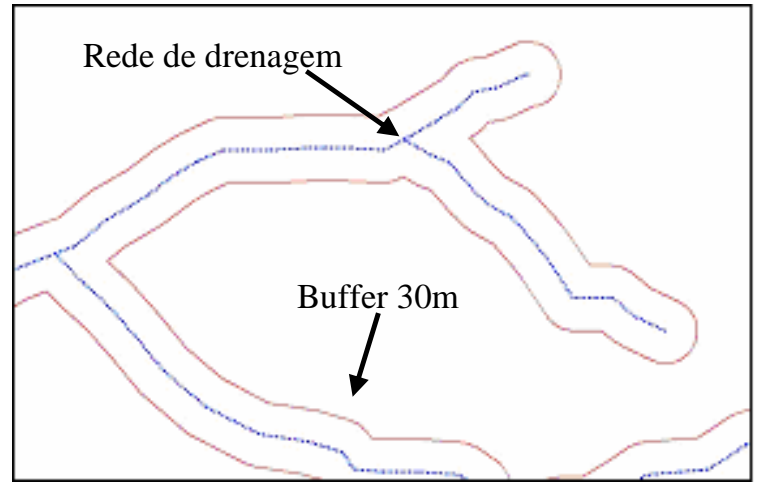

Figura 2. Exemplo da vetorização da rede de drenagem e geração do mapa de distância, com delimitação de 30m a partir das margens dos rios no SPRING.

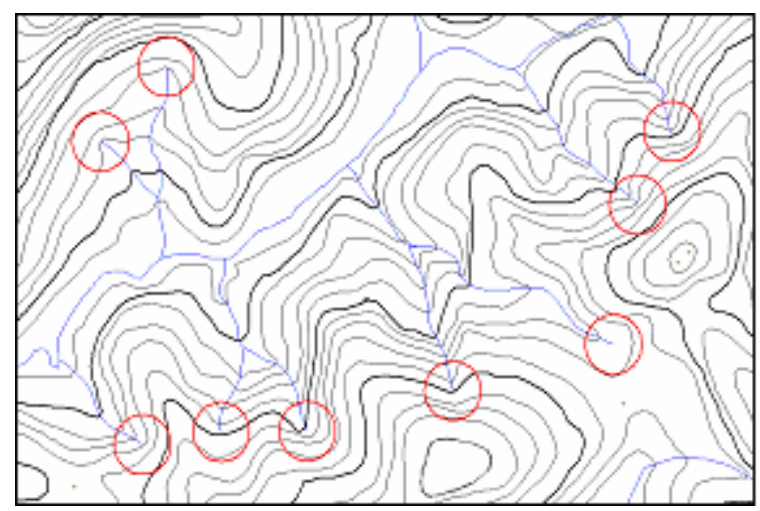

Figura 4. esemplo da delimitação de APPs de nascentes com raio de 50m no SPRING.

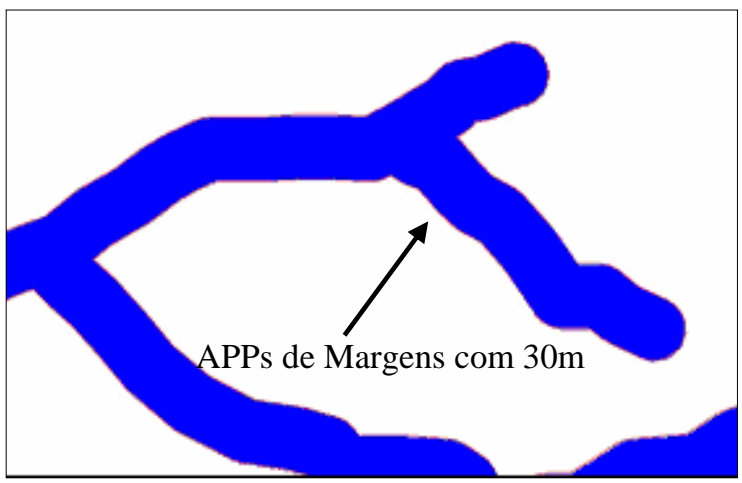

Figura 3. Exemplo de mapeamento de APP de margens de rios com faixa de 30m no SPRING.

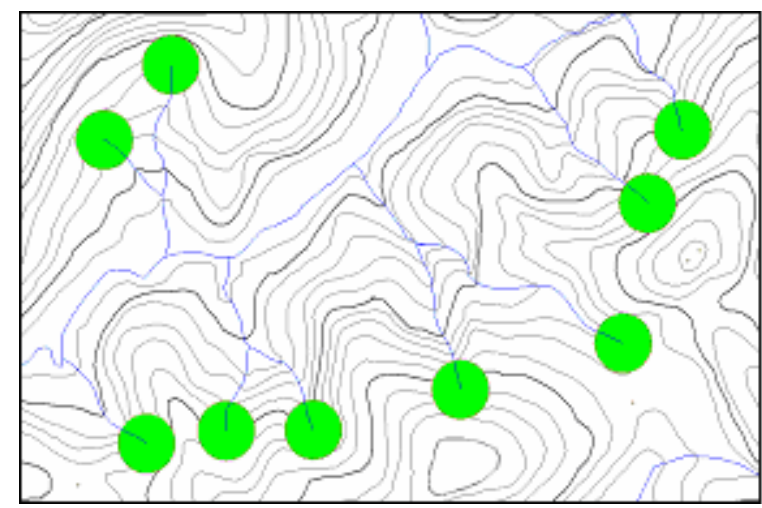

Figura 5. Exemplo do mapeamento de APPs de nascentes com raio de 50m no SPRING.

A Figura 8 apresenta um conjunto de detalhes de interpretação da classe de APP Topo de Morros utilizando-se o SPRING na versão 4.2.

A Figura 9 mostra um detalhe ampliado do mapeamento de todas as classes de APPs que ocorrem no município, exceto a APP de altitude maior que $1800 \mathrm{~m}$.

Os resultados obtidos da classificação das diversas classes de APPs (Figura 9) na execução deste trabalho levaram em consideração as definições de APPs previstas em Leis Federais, há que se ressaltar que os Estados e Municípios, por meio de seus órgãos ambientais responsáveis, têm competência para estabelecer normas e procedimentos mais restritivos. Portanto, as áreas de APPs, se avaliadas com base nas legislações estadual e municipal, poderão aumentar em função dessas restrições adicionais. 
CATELANI, C. S.; BATISTA, G. T. Mapeamento das Áreas de Preservação Permanente (APP) do município de Santo Antônio do Pinhal, SP: um subsídio à preservação ambiental. Ambi-Agua, Taubaté, v. 2, n. 1, p. 30-43, 2007. (doi:10.4136/ambi-agua.18)

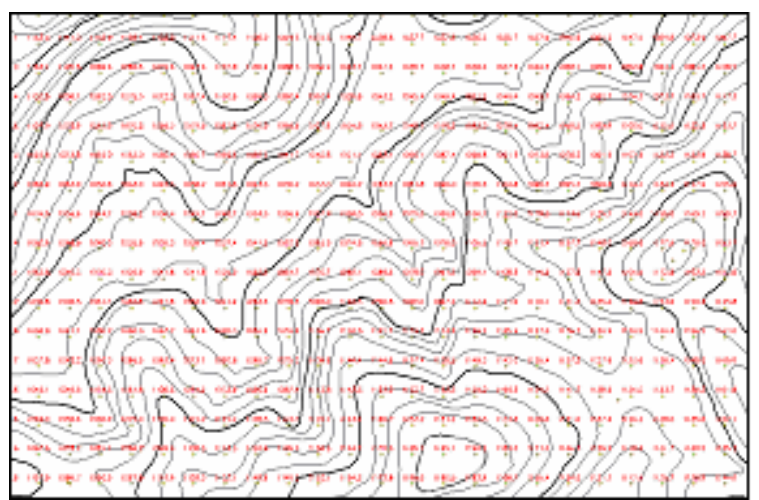

Figura 6. Detalhe da Grade Regular do Modelo Digital do Terreno no SPRING.

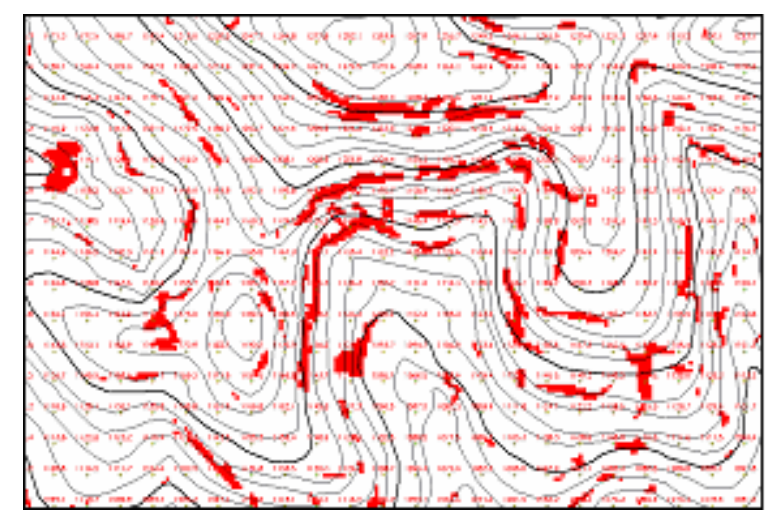

Figura 7. Exemplo do mapeamento de APPs de declividade superior a 45 graus no SPRING.

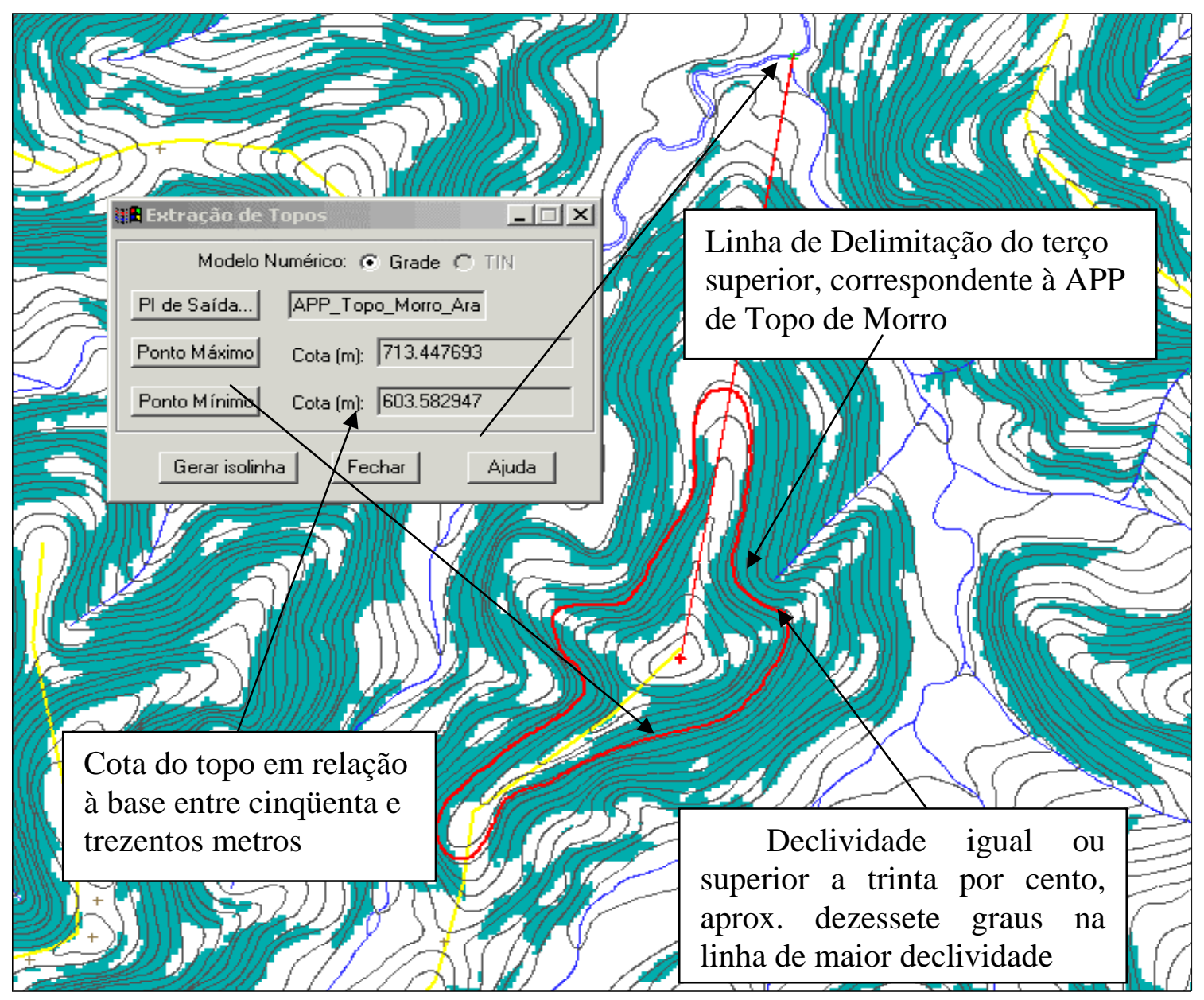

Figura 8. Detalhes dos elementos avaliados na interpretação da classe de APP de Topo de Morros, utilizando-se o software SPRING (Câmara et al., 1996).

Há que se considerar também, em adição, as áreas de reserva legal que correspondem a 20\% da área das propriedades rurais nesse município. É bom salientar ainda que as informações de APPs de topo de morro encontram-se no ponto de maior complexidade tanto no entendimento de seus limites reais e legais, quanto na sua delimitação espacial (Moreira et al., 2003). 
Em consonância com os objetivos deste trabalho, foram mapeadas as classes de APPs, na escala de 1:50.000 (Figura 10), e as áreas de cada classe de APP são apresentadas na (Tabela 1). Pode-se notar que a classe Topo de Morros ocupa uma área de 4.227 ha equivalentes a 30,7\% do total do município, isso demonstra claramente a importância dessa classe de APP em relação às demais. Esse fato foi também evidenciado por outros autores em análises semelhantes (Nascimento et al., 2005, Ribeiro et al., 2005) o que leva a uma reflexão sobre a importância dessa classe de APP, especialmente, no domínio geomorfológico dos mares de morros, onde se insere este município e onde a tradição de uso do solo é tipicamente conflitante com a necessidade de preservação.

Mapeamentos, como os apresentados neste artigo, são essenciais para a gestão municipal, especialmente, para subsidiar o plano diretor, uma vez que essas áreas têm restrição legal de uso.

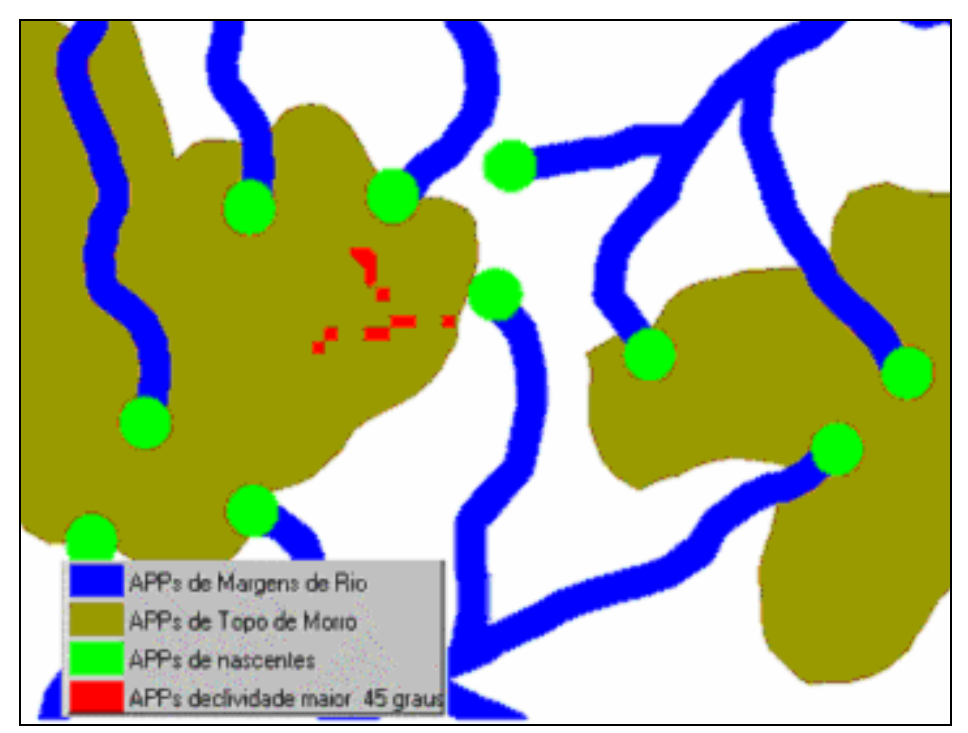

Figura 9. Exemplo dos polígonos temáticos resultantes do mapeamento das Áreas de Preservação Permanente do Município de Santo Antônio do Pinhal, SP.

Embora haja propostas de delimitação de APPs de topo de morro de forma automatizada (Hott et al., 2005; Ribeiro et al., 2002, 2005), ferramentas disponíveis no SPRING foram funcionais para a determinação dessa classe de APP, uma vez que essa operação envolve aspectos interpretativos da legislação que dependem de situações localizadas. 
CATELANI, C. S.; BATISTA, G. T. Mapeamento das Áreas de Preservação Permanente (APP) do município de Santo Antônio do Pinhal, SP: um subsídio à preservação ambiental. Ambi-Agua, Taubaté, v. 2, n. 1, p. 30-43, 2007. (doi:10.4136/ambi-agua.18)

Tabela 1. Área das classes de Áreas de Preservação Permanente do Município de Santo Antônio do Pinhal.

\section{Área das APPs}

\begin{tabular}{lrcc}
\hline \multicolumn{1}{c}{ Classes de APPs } & Área (ha) & \% das APPs & \% das APPs no Município \\
\hline Nascentes & 328 & 4,6 & 2,4 \\
Margens (30m) & 2585 & 35,8 & 18,8 \\
Inclinação > 45 & 24 & 0,3 & 0,2 \\
Altitude > 1800m & 41 & 0,7 & 0,3 \\
Topos de Morros & 4227 & 58,6 & 30,7 \\
\hline TOTAL de APPs & $\mathbf{7 2 1 8}$ & $\mathbf{1 0 0 , 0}$ & $\mathbf{5 2 , 3}$ \\
\hline
\end{tabular}

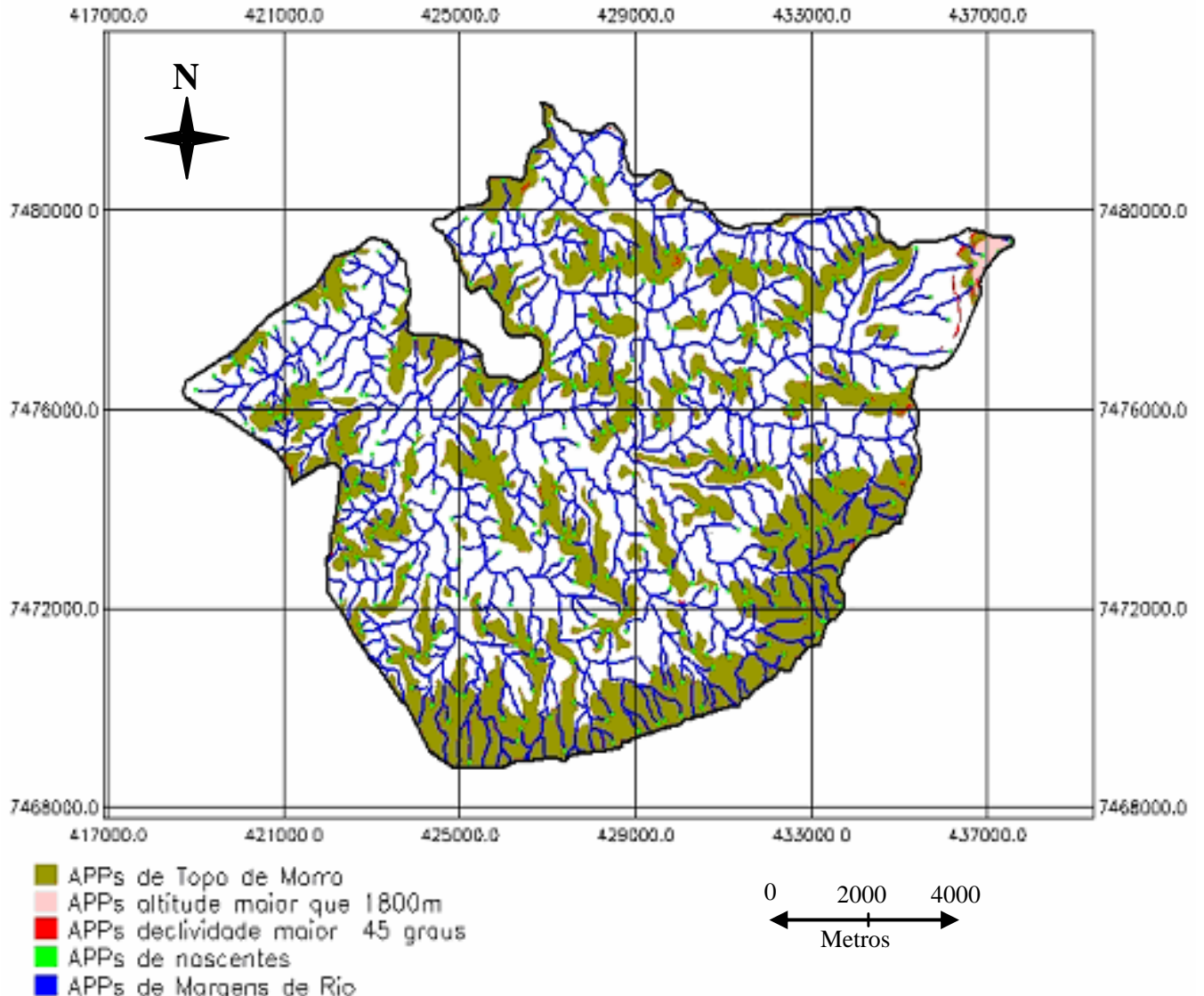

Figura 10. Mapa das Áreas de Preservação Permanente (APPs) do município de Santo Antônio do Pinhal, SP. 


\section{CONCLUSÕES}

A partir dos estudos realizados neste trabalho, pôde-se chegar às seguintes conclusões:

O município de Santo Antônio do Pinhal apresenta na escala de trabalho de 1:50.000 um total de 7.218 ha de áreas de preservação permanente (APPs) o que equivale a 52,3\% da área do município;

A determinação de APPs referentes aos topos de morros, montes, serras e montanhas requerem grande esforço interpretativo do analista e, portanto, recomenda-se precaução no uso dos resultados referentes a essa classe;

O mapa de APPs é fortemente dependente da escala de trabalho e resolução da grade do modelo numérico do terreno usado na delimitação dessas áreas. Portanto, os resultados aqui reportados se referem à escala de trabalho de 1:50.000, em que foram utilizadas curvas de nível com eqüidistância vertical de 20m e grade regular de MNT também com 20m de resolução;

Para delimitação de áreas de APP do município é fundamental trabalhar com o modelo digital do terreno e rede de drenagem além dos limites municipais, pois a linha de base para a delimitação dos topos de morro pode estar fora do município;

A espacialização dos limites das classes de APPs de Topo de Morro e linhas de cumeada é subjetiva e, portanto, objeto de interpretação;

Ferramentas de sistemas de informação geográfica (SIGs) como as disponíveis no software SPRING foram essenciais para a verificação e mapeamento de áreas de preservação permanente ao nível municipal ou regional.

\section{REFERÊNCIAS}

AULICINO, L. C. M.; RUDORFF, B. F. T.; MOREIRA, M. A.; MEDEIROS, J. S.; SIMI JR., R. Subsídios para o manejo sustentável da bacia hidrográfica do rio Una através de técnicas de geoprocessamento e de sensoriamento remoto. In: SIMPÓSIO LATINOAMERICANO DE PERCEPCIÓN REMOTA, 9., 2000, Puerto Iguazu. Memórias... . Lujan: SELPER, 2000. p. 899-908.

BRASIL. Decreto-lei no 4.771, de 15 de setembro de 1965. Institui o Novo Código Florestal Brasileiro e dá outras providências. Diário Oficial da União DOU de 16 de setembro de 1965. Brasília DF. 1965.

BRASIL. Conselho Nacional do Meio Ambiente. Resolução nº 4, de 18 de setembro de 1985. Tendo em vista o que estabelece a Lei 4.771, de 15 de setembro de 1965, alterada pela lei 6.535, de 15 de junho de 1978, e pelo que determina a Resolução CONAMA 008/84 estabelece critérios para as Áreas de Preservação Permanente. Diário Oficial da União DOU de 20 de janeiro de 1986. Brasília DF, 1986.

BRASIL. Conselho Nacional do Meio Ambiente. Resolução nº 303, de 20 de março de 2002. Dispõe sobre parâmetros, definições e limites de Áreas de Preservação Permanente. Diário Oficial da União DOU de 13 de maio de 2002. Brasília DF, 2002.

BRASIL. Ministério do Planejamento, Orçamento e Gestão. Instituto Brasileiro de Geografia e Estatística. Censo demográfico 2000. Rio de Janeiro: IBGE, 2000. p. 1-520. 
BRASIL. Ministério do Planejamento, Orçamento e Gestão. Instituto Brasileiro de Geografia e Estatística. Superintendência de Cartografia. Carta Tremembé (SP): SF 23-Y-B-V-4. 1974. In:__ Carta do Brasil. Rio de Janeiro: IBGE, 1974. Escala 1:50.000. Projeção Universal Transversa de Mercator.

BRASIL. Ministério do Planejamento, Orçamento e Gestão. Instituto Brasileiro de Geografia e Estatística. Superintendência de Cartografia. Carta Monteiro Lobato (SP-MG): SF-23Y-B-V-3, 1973. In: Carta do Brasil. Rio de Janeiro: IBGE, 1973. Escala 1:50.000. Projeção Universal Transversa de Mercator.

BRASIL. Ministério da Ciência \& Tecnologia. Convenção sobre mudança do clima: o Brasil e a Convenção Quadro das Nações Unidas. Brasília: MCT, 2002. Disponível em: <http://www.mct.gov.br/index.php/content/view/3888.html>. Acesso em 10 abr. 2006.

CÂMARA, G.; SOUZA, R. C. M.; FREITAS, U. M.; GARRIDO, J. SPRING: Integrating remote sensing and GIS by object-oriented data modelling. Computers \& Graphics, Amsterdam , v. 20, n. 3, p. 395-403, may-jun 1996.

COSTA, T.; COSTA, C.; SOUZA, M. G.; BRITES, R. S. Delimitação e caracterização de áreas de preservação permanente por meio de um sistema de informações geográficas (SIG). Revista Árvore, Viçosa, v. 20, n. 1, p. 129-135, 1996.

HOTT, M. C.; GUIMARÃES, M. M.; MIRANDA, E. E. Um método para a determinação automática de áreas de preservação permanente em topos de morros para o Estado de São Paulo. In: SIMPÓSIO BRASILEIRO DE SENSORIAMENTO REMOTO, 12., 16-21 abril 2005, Goiânia. Anais... Goiânia: INPE, 2005. p. 3061-3068.

KRONKA, F. J. N.; NALON, M. A.; MATSUKUMA, C. K.; KANASHIRO, M. M.; YWANE, M. S. S. I.; LIMA, L. M. P. et al. Monitoramento da vegetação natural e do reflorestamento no Estado de São Paulo. In: SIMPÓSIO BRASILEIRO DE SENSORIAMENTO REMOTO, 12., 16-21 abril 2005, Goiânia. Anais... São José dos Campos: INPE, 2005. p. 1569-1576.

KURKDJIAN, M. L. N. O.; VALÉRIO FILHO, M.; VENESIANI, P.; PEREIRA, M. N.; FLORENZANO, T. G.; ANJOS, C. E. dos et al. Macrozoneamento da Região do Vale do Paraíba e Litoral Norte do Estado de São Paulo. São José dos Campos: INPE, 1992. 176 p. (INPE-5381- PRP/165).

MIGUEZ, J. D. G. O mecanismo de desenvolvimento limpo: a proposta e as perspectivas brasileiras. In: ENCONTRO: SUSTENTABILIDADE NA GERAÇÃO E USO DE ENERGIA NO BRASIL: OS PRÓXIMOS VINTE ANOS, 18-20 fev. 2002, Campinas. Anais... Campinas: UNICAMP, 2002. Disponível em: http://libdigi.unicamp.br Acesso em 22 maio. 2006.

MOREIRA, A. A.; SOARES, V. P.; RIBEIRO, J. C.; RIBEIRO, C. A. A. S.. Determinação de áreas de preservação permanente em uma microbacia hidrográfica a partir de fotografias aéreas de pequeno formato. In: SIMPÓSIO BRASILEIRO DE SENSORIAMENTO REMOTO, 11., 5-10 abr. 2003, Belo Horizonte. Anais... São José dos Campos: INPE, 2003. p. 1381 - 1389. CD-ROM, On-line. Publicado como: INPE--PRE/. Disponível em: <http://marte.dpi.inpe.br:80/rep-/ltid.inpe.br/sbsr/2002/11.12.11.06>. Acesso em 05 abr. 2006. 
NASCIMENTO, M. C.; SOARES, V. P.; RIBEIRO, C. A. A. S.; SILVA, E. Delimitação automática de áreas de preservação permanente (APP) e identificação de conflito de uso da terra na bacia hidrográfica do rio Alegre. In: SIMPÓSIO BRASILEIRO DE SENSORIAMENTO REMOTO, 12., 16-21 abr. 2005, Goiânia. Anais... São José dos Campos: INPE, 2005. p. 2289-2296. CD-ROM, On-line. Disponível em: <http://marte.dpi.inpe.br:80/rep-/ltid.inpe.br/sbsr/2004/10.18.18.26>. Acesso em 05 abr. 2006.

OLIVEIRA, I. S.; BATISTA, G. T., CATELANI, C. S.. Minicurso: Área de Preservação Permanente (APP). In: ENCONTRO ÁGUA \& FLORESTA, 7-9 nov. 2006, Taubaté. Repositório Eletrônico Ciências Agrárias. Taubaté: UNITAU, 2006. 78p. (Coleção Ciências Florestais). Disponível em: <http://hdl.handle.net/2315/66>. Acesso em 27 mar. 2007).

PINCINATO, F. L. Sensoriamento remoto e SIG na análise da viabilidade de recuperação de áreas de preservação permanente irregulares em São Sebastião - SP. In: SIMPÓSIO BRASILEIRO DE SENSORIAMENTO REMOTO, 12., 16-21 abr. 2005, Goiânia. Anais... Goiânia: INPE, 2005. p. 2323-2330.

REBOUÇAS, A. C.; BRAGA, B.; TUNDISI, J. G. Águas doces no Brasil: capital ecológico, uso e conservação. São Paulo: Escrituras, 1999. 717 p.

RIBEIRO C. A. A. S.; SOARES, V. P.; OLIVEIRA, A. M. S.; GLERIANI, J. M.O. Desafio da delimitação de áreas de preservação permanente. Revista Árvore, Viçosa, v. 29, n. 2, p. 203-212, 2005.

RIBEIRO, C. A. A. S.; OLIVEIRA, M. J. de; SOARES, V. P.; PINTO, F. de A. de C. Delimitação automática de áreas de preservação permanente em topos de morro e em linhas de cumeada: metodologia e estudo de caso. In: SEMINÁRIO DE ATUALIZAÇÃO EM SENSORIAMENTO REMOTO E SISTEMAS DE INFORMAÇÕES GEOGRÁFICAS APLICADOS À ENGENHARIA FLORESTAL, 5., 2002, Curitiba. Anais... Curitiba: FUPEF, 2002.

SAITO, M. A. Manejo de pastagens: recursos naturais: caracterização e conservação. Campinas: Instituto Agronômico de Campinas, 1995. 143 p. cap. 1.

SÃO PAULO (Estado). Coordenadoria de Assistência Técnica Integral. Centro de Informações agropecuárias. Levantamento das unidades de produção agropecuária: estatísticas agrícolas - Estado de São Paulo 1995/96. Campinas, 1996. Disponível em: <http://www.cati.sp.gov.br/servicos/lupa/m_lupa.htm>. Acesso em 14 mar 2006.

VICTOR, M. A. M. A devastação florestal em São Paulo. São Paulo. Sociedade Brasileira de Silvicultura, 1979. 48p. 